\title{
Who's your patty? Consumer acceptance and sensory properties of burger patties made with different types of meat or plant-based products
}

\author{
Shannon Rohall, Jennifer Ballintine, Jessica Vowels, Linsday Wexler, Keiko Goto \\ California State University, Chico
}

\begin{abstract}
Having more healthful options at campus eateries is a viable way to meet consumer demand, as well as to promote health on campus. Our study tested three healthier alternatives (low-fat beef, turkey, and soy/rice burgers) against the conventional full-fat hamburger patty (control). We examined consumer acceptance of the four burger patties with 48 untrained student panelists. A 9-point scale hedonic test was used to measure consumer acceptance. Quantitative descriptive analysis (QDA) was also conducted with six trained panelists to evaluate the intensity of sensory properties. Analysis of variance was used to detect significant differences among the treatments. Consumer acceptance mean scores for full-fat beef, lean beef, turkey, and soy/rice patties were 5.98, 6.68, 5.50 and 5.56, respectively, with no preference of the control patty over turkey or soy/rice, but a significant preference of the lean beef over turkey and soy/rice. QDA results showed flavor, spiciness, and elasticity significantly varied across the treatments. Panelists rated lean beef as significantly more elastic than all other patties. It is uncertain whether those sensory attributes contributed to consumer acceptance. In conclusion, our research indicates that college consumers may accept these healthier substitutes for traditional full-fat beef patties. Consumer acceptance of healthier patty substitutes should be further investigated in primary and secondary schools as well. With proper marketing, healthier alternatives to the conventional, full-fat hamburger patty could become competitive choices.
\end{abstract}

(C) 2009 Californian Journal of Health Promotion. All rights reserved.

Keywords: College health, Sensory evaluation, Lean protein, Consumer acceptance, Quantitative descriptive analysis

\section{Introduction}

Obesity is on the rise in the United States. About 66 per cent of adults age 20 and older are overweight or obese in the U.S. (NCHS, 2008). Although these rates are somewhat lower with $27 \%$ of women and $39 \%$ of men being either overweight or obese in the college population, (American College Health Association, 2009), college students are at high risk of overweight and obesity due to dynamic changes in their levels of physical activity and energy intake (Haberman \& Luffey, 1998).

In Fall of 2008, marketing research on foods served at campus dining facilities was conducted at a northern California university. The results of this research indicated that a significant number of campus consumers considered the local concession's beef burger as "not tasty" and "unhealthy" and were interested in having more vegetarian and lower fat options (Boek, BiancoSimeral, Chan, \& Goto, unpublished data). Because a 250 calorie deficit per day can lead to a half a pound a week weight loss, offering lower-fat burger patty alternatives is a viable way to meet this consumer demand, as well as to promote health on campus through leaner protein sources.

Previous studies indicate consumers do not always detect differences between healthy and unhealthy foods (Wagner, Senauer, \& Runge, 2007). Furthermore, directly pertaining to burger patties, another study concluded that the "juiciness" of low-fat beef patties, rated by six trained panelists, increased with the addition of soluble fiber (Serdaroglu, 2005). Hence, with 
the right amount of soluble fiber and fat, a burger patty can be both healthier and well liked. Other research has also shown that treatments with vegetarian protein substitutes are equally well accepted by adult consumers (Bordi, Lambert, Devitis, Chen, \& Conley, 2002).

In our study, we chose to modify the type of burger patty to create three healthier alternatives (low-fat beef, turkey, and soy/rice burgers) to the conventional, full-fat hamburger patty (control). The objective of this study was to examine whether any of the three alternatives could be substituted for the original without any decrease in consumer acceptance and/or the quality of sensory properties. We tested the sensory quality of these four types of burgers as perceived by both untrained student consumers and trained panelists using two sensory evaluation methods; hedonic testing and quantitative descriptive analysis (QDA).

\section{Methods}

\section{The formation of four burger patties}

For our materials, the control burgers (full-fat) came frozen from the University's food court. The lean beef burgers ( $4 \%$ fat) and turkey burgers also came frozen from a chain grocery store. All patties were cooked the same way

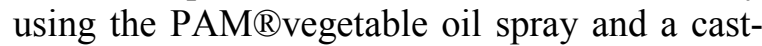
iron griddle.

The beef patties were cooked to an internal temperature of $160^{\circ}$ Fahrenheit, and the turkey burgers were cooked to $165^{\circ}$, as recommended by the Food Safety and Inspection Services (2007). Because the soy/rice patties did not have any temperature recommendations, doneness was determined by an external light brown shade on top and bottom and internal solidity.

The soy/rice burgers were the only patties that were modified, being initially soy protein isolate based. To make a batch (332 g), 24 grams of dry ground soy protein isolate was soaked in 265 $\mathrm{ml}$ of boiling water for 10 minutes. Then, 26 grams of coarsely ground instant brown rice was cooked for approximately 10 minutes. Brown rice was added to increase the coarseness of the patty texture from a consistency similar to pureed meat to a consistency nearer to ground meat. For flavor, $14.8 \mathrm{ml}$ of soy sauce, $1.2 \mathrm{~g}$ of chili powder, $2.4 \mathrm{~g}$ of garlic powder, $1.2 \mathrm{~g}$ of black pepper, $6 \mathrm{~g}$ of salt, and $2.4 \mathrm{~g}$ of oregano were used per batch (332 g). Next, $68 \mathrm{~g}$ of flour was added to the completed mixture to thicken it and bind all ingredients together.

\section{Sensory evaluations}

This study was approved by the Institutional Review Board at California State University, Chico and all data were collected as part of a class project. A complete block design was used to evaluate data. Sensory evaluation preparation included: 1) Setting-up the evaluation room with isolation booths, chairs, and red lights; 2) Labeling sample plates with 3-digit random numbers for all treatments; and 3) On serving trays placing one sample plate from each of the four treatments, a napkin, one cup of water, a pencil, and an evaluation survey.

Hedonic testing was used to assess the consumer acceptance of the four burgers among untrained panelists. The treatments consisted of the burger patty and a standard, sesame seed hamburger bun. No condiments were included as it was thought that the addition of condiments might mask the actual flavor of the burger patties. These burgers were then cut into quarters. The hedonic tests are based on a 9-point Likert scale ranging from (9) "like extremely" to (1) "dislike extremely." Fifty untrained panelists, all of whom were college students ages 18 to 26 and $60 \%$ of whom were male, evaluated the burgers. The panelists were instructed to taste samples from left to right and to take water between each sample. The serving order of burgers was also rotated to reduce potential bias caused by positions. The panelists rated each sample using the corresponding numbers on their surveys. Two panelists were discounted due to incomplete data.

Quantitative descriptive analysis (QDA) was also performed by six trained panelists who were nutrition major students to evaluate the sensory attributes of the four types of patties. The students were trained in four two-hour sessions using the methods suggested by Lawless and 
Heymann (1998). Eight sensory attributes were identified and defined by the panelists and researchers (see Figure 1 for details). After the four training sessions were completed, the patty samples were evaluated by the panelists using the QDA method. The six trained panelists were provided with a quarter of each patty and a QDA evaluation sheet. After tasting each sample, panelists placed a vertical mark on a linear scale with two opposing anchor words for their perceived intensity of each attribute. The line spectrum was numerically converted into values of $0-10$, read left to right.

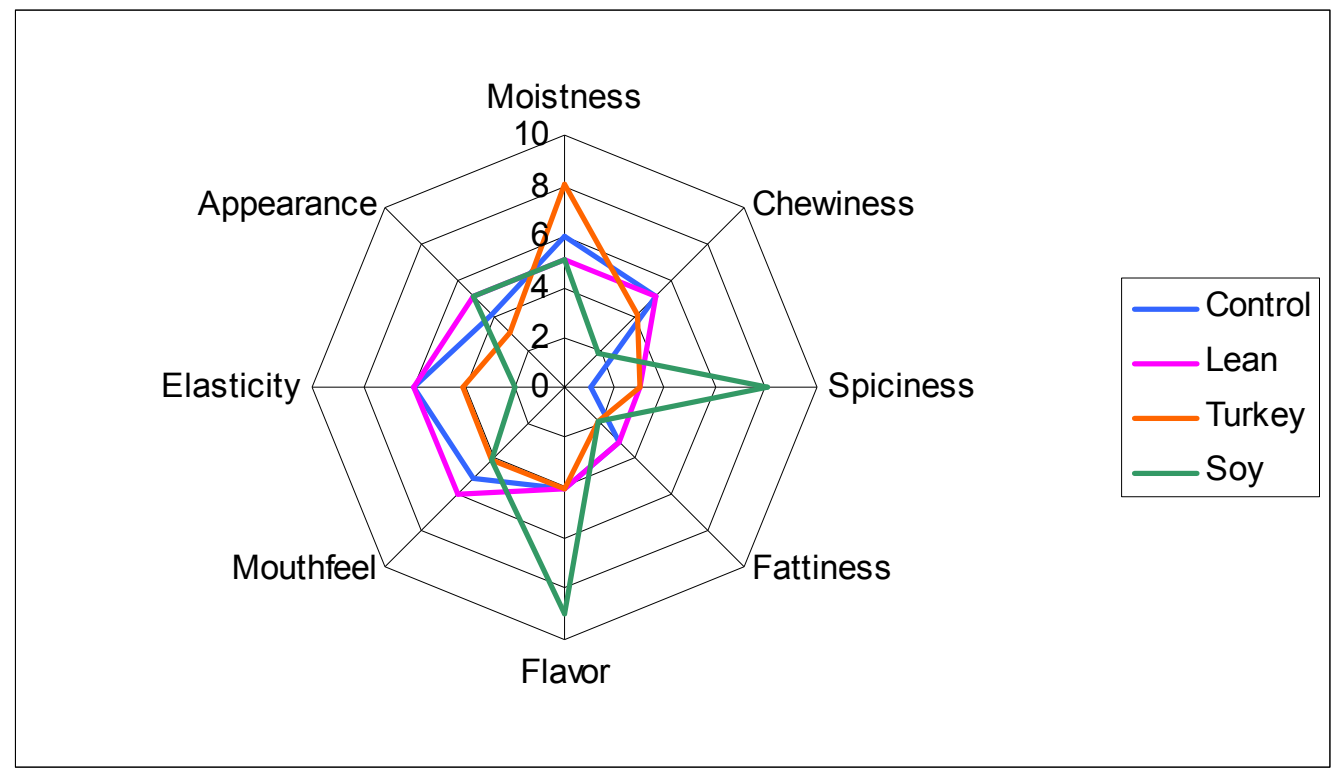

Figure 1: Sensory profiles of four burger patties based on quantitative descriptive analysis*

*Anchor words for each attributes are as follows:

Chewiness: Crumbly (0) - chewy (10), Spiciness: Bland (0) - very spicy (10), Fattiness/oiliness: Not at all (0) - Very fatty (10), Flavor: Not at all (0) - Very flavorful (10), Coating mouthfeel: Not at all (0) - Very high (10), Elasticity: Flat (0) - Very elastic (10), Appearance: Smooth (0) - bumpy (10), Moistness: Dry (0) - Very moist (10)

\section{Data analysis}

Data were analyzed using SPSS (version 15.0 for Windows, SPSS Inc., Chicago, IL, 2006). Analysis of variance (ANOVA) was used to establish significant differences among the burger treatments followed by the Tukey's multiple comparison test. Panelists were considered random effects, and the type of the burger patties was considered a fixed effect (Lawless and Heymann, 1998). In addition, the effect of gender on consumer acceptance was examined using multivariate analysis of variance (MANOVA). A p-value of less than or equal to 0.05 was set as the level of significance. In addition, nutritional content of each patty was assessed using software Diet Analysis Plus (6.0 Online Version, Windows/Mac, ESHA Research, 2002).

\section{Results}

\section{Nutritional Analysis}

The lean beef patty had $4.5 \mathrm{~g}$ of fat $(4 \%)$ and 150 kcal per serving $(=110 \mathrm{~g})$ versus $22 \mathrm{~g}$ of fat $(20 \%)$ and $309 \mathrm{kcal}$ in the control. Of those grams of fat, the lean beef patty only had $1.5 \mathrm{~g}$ of saturated fat, whereas the control had $9 \mathrm{~g}$. The turkey patty had 9 grams of total fat $(8.2 \%), 2.5$ $\mathrm{g}$ of saturated fat, and $160 \mathrm{kcal}$, while the soy/rice patty only had 1 gram of fat $(0.9 \%)$, no saturated fat, and $118 \mathrm{kcal}$. As it stands, any of the alternatives to the control would result in a significant reduction of calories, namely due to fat.

\section{Consumer acceptance test}

Overall significant differences $(\mathrm{P}=0.015)$ were 
found among the four treatments. Of the four treatments, the control, turkey, and soy/rice were perceived to be equally acceptable options by the campus consumers, with mean scores of $5.98,5.50$, and 5.56, respectively (Table 1). There was no significant difference in acceptance among the three treatments. On the other hand, the lean-beef patty was significantly preferred over all turkey and soy/rice, with a mean of 6.68 , which translates to an overall opinion of between "Like slightly" and "Like moderately" (Table 1). In addition, gender was not a significant factor affecting acceptance among our study participants $(\mathrm{P}=0.74)$.

Table 1. Mean scores of the sensory evaluations of meat treatments (hedonic and QDA)

\begin{tabular}{|l|l|l|l|l|}
\hline Type of Patty & Acceptance & Flavor $^{2}$ & Spiciness $^{3}$ & Elasticity $^{4}$ \\
\hline Control (full-fat) & $5.98 \pm 1.86^{\mathrm{a}^{\mathrm{b}^{*}}}$ & $4.5 \pm 1.51^{\mathrm{a}}$ & $1.17 \pm 0.75^{\mathrm{a}}$ & $4.5 \pm 2.26^{\mathrm{ab}}$ \\
\hline Lean & $6.68 \pm 1.43^{\mathrm{b}}$ & $3.33 \pm 1.86^{\mathrm{a}}$ & $2.17 \pm 1.47^{\mathrm{a}}$ & $6.16 \pm 2.40^{\mathrm{b}}$ \\
\hline Turkey & $5.50 \pm 2.21^{\mathrm{a}}$ & $3.66 \pm 1.21^{\mathrm{a}}$ & $2.67 \pm 1.97^{\mathrm{a}}$ & $3.33 \pm 1.21^{\mathrm{ab}}$ \\
\hline Soy/rice & $5.56 \pm 2.67^{\mathrm{a}}$ & $8.5 \pm 0.54^{\mathrm{b}}$ & $8.0 \pm 1.26^{\mathrm{b}}$ & $2.0 \pm 1.55^{\mathrm{ac}}$ \\
\hline
\end{tabular}

(1) Acceptance score: $1=$ dislike extremely, $9=$ like extremely, (2) Flavor score: $0=$ bland $10=$ very flavorful

(3) Spiciness score: $0=$ not at all, $10=$ very spicy, (4) Elasticity score: $0=$ flat, $10=$ very elastic

* Different letters show significant differences according to Tukey's test $(\mathrm{P}<0.05)$.

\section{Quantitative Descriptive Analysis (QDA)}

QDA results did not display any significant differences in five of the eight characteristics. For example, although the turkey burger was perceived to be moister than the other treatments (Figure 1), the difference was not statistically significant among the four treatments. Flavor, spiciness, and elasticity were three sensory attributes that significantly varied across the four treatments (Table 1). The Soy/rice burger was rated to be, by far, the most flavorful and spicy treatment, with means of 8.5 and 8.0 respectively. This is expected, as no other patties were seasoned. Regarding the elasticity of the patties, the lean-beef patty was significantly more elastic (mean score $=6.16$ ) than the soy/rice patty (mean score $=2.0$ ). While the lean beef burger was significantly preferred over soy/rice and turkey burgers among untrained consumers, it is not clear whether elasticity contributed to high acceptance of the lean beef burgers.

\section{Discussion}

Our study results indicate that any of the three alternatives could be substituted for the original without any decrease in consumer acceptance. To our knowledge, this is the first study that evaluated consumer acceptance of burger patties. Our study results were in accordance with the previous studies in which consumers were unable to tell the difference between regular and low fat alternatives and that consumer acceptance of plant-based alternatives to conventional full-fat items was not rated differently from the control (Bordi et al., 2002; Wagner et al., 2007; Pérez-Palacios, Martin, Ruiz, \& Antequera, 2008). This is encouraging since any of the alternatives to the control would result in a significant reduction of calories, mainly from fat.

Soy/rice burgers received general customer approval and many people gave them positive ratings, a result that was anticipated from another study assessing consumer acceptance of plant based protein substitutes (Bordi, et al., 2002). Furthermore, our QDA results indicate that the soy/rice burger was significantly more spicy and flavorful than the other three treatments. Some of the panelists, who are not accustomed to drastic changes in burger flavor, 
may not have accepted the soy/rice as much, whereas others welcomed the new change.

Interestingly, the lean beef burger was significantly preferred over soy/rice and turkey burgers. The lean beef patty was also perceived to be the most elastic among the four treatments. It is unclear whether elasticity or some other sensory attributes of the lean beef patty significantly contributed to its high acceptance. Further studies are needed to examine the relationship between sensory properties rated by trained panelists and untrained consumers' preference.

Our study has several limitations. First, our complete block design only included panelists who were willing to taste both vegetarian and non-vegetarian burgers. Second, convenience sampling of study participants was used, and the sample size was relatively small. Finally, seasoning was used for one patty (soy/rice), but not the others. If this study were to be conducted again, we might consider adding the same amount of seasoning to each patty. Also, we might develop patties with different amounts of seasoning to examine its effects on consumer acceptance.

\section{Implications of the study for health promotion}

We have met our objective by creating healthier and acceptable products that may be able to replace the patty burger that is served at campus dining. Because of the continued increase in the rates of overweight/obesity and chronic diseases in America, any reduction in calories, fat and cholesterol will be beneficial. Our research indicates that college consumers may accept these healthier substitutes for traditional full-fat beef patties. Consumer acceptance of healthier patty substitutes should be investigated in primary and secondary schools as well. With proper marketing, healthier alternatives to the conventional, full-fat hamburger patty could become competitive choices. These substitutes may also help to fulfill the nutrition requirements of the school lunch programs for leaner protein sources. On the other hand, the possible financial, political, and regulatory constraints under which dining services operate need to be examined. For example, leaner beef patties are more expensive than full-fat beef patties. Further studies are needed to examine consumer acceptance testing coupled with effective marketing strategies of the health benefits of the products among college students, as well as primary and secondary school students.

\section{Acknowledgements}

The authors thank the study participants, Stephanie Bianco-Simeral, and Kelly Fiori for their support.

\section{References}

American College Health Association (2009). National College Health Assessment Spring 2008 Reference Group Data Report (Abridged). Journal of American College Health, 57, 477-488.

Boek, S., Bianco-Simeral, S., Chan, K., \& Goto, K. Consumer acceptance of pepperoni pizza among college students. Unpublished data.

Bordi, P.L., Lambert, C., Devitis, C. A., Chen, P., \& Conley, C. (2002). Sensory Comparison of a soy enhanced chocolate candy and a regular chocolate candy. Foodservice Research International, $13,193-201$.

Food Safety and Inspection Services (2007). Is it Done Yet? http://www.fsis.usda.gov/PDF/IsItDoneYet_Magnet.pdf Accessed November 30, 2008.

Haberman, S. \& Luffey, D. (1998). Weighing in college students' diet and exercise behaviours. Journal of the American College of Health, 46, 189-191.

Lawless, H.T. \& Heymann, H. (1998). Sensory Evaluation of Food Principles and Practice. Chapman \& Hall, New York, NY. 
National Center for Health Statistics (2008). Prevalence of overweight, obesity and extreme obesity among adults: United States, trends 1960-62 through 2005-

2006.http://www.cdc.gov/nchs/data/hestat/overweight/overweight_adult.htm Accessed September 24, 2009.

Pérez-Palacios, T., Martin, D., Ruiz, J., Antequera, T. (2008). Comparison of different methods for total lipid quantification in meat and meat products. Food Chemistry, 110, 1025-1029.

Serdaroglu, M. (2005). The characteristic of beef patties containing different levels of fat and oat flour. International Journal of Food Science and Technology, 41, 147-153.

Wagner, B., Senauer, B., Runge, C. F. (2007). An Empirical Analysis of and Policy Recommendations to Improve the Nutritional Quality of School Meals. Review of Agricultural Economics, 29, 672688.

Author Information

Shannon Rohall, B.S.

Department of Nutrition and Food Sciences

California State University, Chico

Jennifer Ballintine

Department of Nutrition and Food Sciences

California State University, Chico

Jessica Vowels

Department of Nutrition and Food Sciences

California State University, Chico

Linsday Wexler

Department of Nutrition and Food Sciences

California State University, Chico

*Keiko Goto, PhD

Assistant Professor

Department of Nutrition and Food Sciences

California State University, Chico

100 West 1st St.

Chico, CA 95929-0002

Phone: (530)-898-6767

Fax: (530)-898-5586

E-mail: kgoto@csuchico.edu

* corresponding author 